Crítica da contemporaneidade 



\section{Guerra, religião, secularismo e alguns sujeitos sensíveis: reflexões preliminares a partir de Talal Asad ${ }^{1}$}

Patrícia Birman ${ }^{2}$

Resumo: 0 artigo procura discutir a forte associação entre guerra e religião, inspirando-se na obra de Talal Asad, autor que reconfigurou os estudos da religião ao explorar os vínculos constitutivos desse campo de estudos com a modernidade secular. Trata-se de interrogar as formações do secular, o modo de sua produção e suas funções no Estado moderno. Considerando o caráter epistemológico das questões do presente, procura-se compreender as aporias do Brasil contemporâneo e, mais especificamente, o sentido moral e religioso da ação política no país e no Rio de Janeiro, nos quais o uso da violência como prática justificada e a promoção da guerra para a destruição dos inimigos, configuram-se como norte de defesa e de construção do estado-nação.

Palavras-chave: Guerra, Religião, Secularismo, Política, Talal Asad.

\section{WAR, RELIGION, SECULARISM AND SOME SENSITIVE SUBJECTS: PRELIMINARY REFLECTIONS FROM TALAL ASAD}

Abstract: The article seeks to discuss the strong association between war and religion, drawing inspiration from the work of Talal Asad, an author who reconfigured the studies of religion by exploring the constitutive links of this field of studies with secular

1 Agradeço imensamente à Cynthia Sarti pelo gentil convite para realizar uma conferência no quadro da Cátedra Edward Saïd, da Universidade Federal de São Paulo, cujo texto serviu de base para tecer e aprofundar os meus argumentos. Agradeço à Márcia Leite que generosamente discutiu comigo o andamento desse trabalho e me fez excelentes sugestões.

2 Professora de Antropologia da Universidade Estadual do Rio de Janeiro (UERJ). 
modernity. It focuses on questioning the formation of the secularism, the mode of their production and functions in the modern state. Considering the epistemological character of the issues of the present, we seek to understand the contemporary Brazil's aporias, and more specifically the moral and religious sense of political action in the country and in Rio de Janeiro, in which the use of violence as a justified practice and the promotion of the war to destroy the enemies are configured as the north of defense and the construction of the nation-state.

Keywords: War, Religion, Secularism, Politics, Talal Asad.

Na campanha eleitoral para presidente do Brasil, o candidato que afinal foi eleito - Jair Bolsonaro - inaugurou uma novidade na política eleitoral brasileira. Optou por utilizar largamente mídias digitais e redes sociais (Facebook, WhatsApp, Twitter, e-mail, entre outras) para atacar os seus concorrentes, disseminando as chamadas fake news. Recusou-se a participar dos debates, desprezando a suposição que esses são essenciais para ganhar as eleições. Há uma novidade tecnológica e política que acompanhou a sua recusa, já se observou. As mídias digitais alteraram mais do que foi possível considerar na época, a saber: o enquadramento da política, seus espaços de ocorrência, a produção dos seus sentidos e a natureza do processo em curso.

Diversos analistas apontaram esses novos métodos na campanha eleitoral como em parte responsáveis por uma mudança substancial no processo mais importante das democracias ocidentais: as eleições. Imagens e discursos acusatórios em profusão tomaram a frente nas mídias sociais. Na esteira das fake news, mensagens fake disparadas por essas mídias sociais teriam sido capazes de atingir seletiva e moralmente os eleitores ${ }^{3}$. Notícias falsas produziram uma população

3 Esse novo modo de fazer campanha não foi inventado no país. Há registros de interferências em campanhas eleitorais vencedoras em outros países. A empresa Cambridge Analytica foi apontada como aquela que teria desenvolvido a tecnologia e as estratégias empregadas para alterar as dinâmicas eleitorais. Apontou-se a campanha do Brexit, na Inglaterra, as eleições do Trump e a do Brasil como tendo sido alvos desses métodos. As fake news dirigiam-se a um público cuidadosamente 
subjetivamente sensível e permeável a outras verdades até então pouco acionadas e valorizadas na esfera pública: o sentido moral e religioso da ação política. Esse sentido ganhou preeminência e favoreceu a ideia de uma forte ruptura a ser concretizada por meio da eleição do candidato de extrema-direita.

A pauta moral não esteve só, longe disso, ela teve primazia e assim permeou todas as outras, dando-Ihes mais consistência ${ }^{4}$. De fato, para a restauração moral necessária, o combate aos inimigos da nação se constituiu como uma evidência. 0 quadro político já era preocupante muito antes do último período eleitoral, com o avanço do conservadorismo de valores já apontado por vários colegas. No período eleitoral, definiu-se de modo mais abrangente os ditos inimigos, seguindo, no entanto, a mesma lógica já amplamente disseminada por meio da segurança pública, nas grandes cidades. Esses setores de diferentes governos nunca hesitaram em promover como orientação prática os lemas que presidem suas ações: "bandido bom é bandido morto" e "direitos humanos para humanos direitos". A promoção da guerra e a consequente destruição daqueles considerados inimigos têm sido exaltadas há longo tempo como projeto de "segurança pública" e de salvação da cidade $^{5}$. A redenção da nação e da cidade se daria pela construção religiosa e moral de todos, foi a novidade ao mesmo tempo secular e cristã que paulatinamente se impôs. Desde os anos 1980, no Rio de Janeiro, quando começaram a se acirrar os conflitos de diferentes grupos de traficantes entre si e com a polícia, os temas da guerra, da religião e da política paulatinamente foram se

escolhido no sentido de mobilizá-lo por meio de acusações basicamente de ordem moral que eram recebidas por meio de seus grupos de confiança, como WhatsApp. Já as questões mais programáticas eram defendidas publicamente pelo candidato e pelos seus seguidores, e incluíam a defesa dos temas clássicos da extrema-direita, além de um incitamento permanente ao uso da violência para combater os inimigos.

4 É interessante, nesse sentido, o livro coletivo Four Lectures on Ethics: Anthropological Perspectives, de Michael Lambeck, Veena Das, Didier Fassin e Webb Keane, publicado pela HAU Books em 2015.

5 SILVA, Luiz Antonio Machado da. O controle do crime violento no Rio de Janeiro. Le Monde Diplomatique, 1 fev. 2013. Disponível em: https://diplomatique.org.br/ocontrole-do-crime-violento-no-rio-de-janeiro/. Acesso em: 6 ago. 2020. 
impondo de forma relacionada. No recente período eleitoral, as dinâmicas em curso foram mais explicitadas e intensificadas. $O$ ataque político aos inimigos, que passaram a incluir novas categorias político-identitárias, foi mais amplo e feroz, transformando-os abertamente em entes despidos de humanidade com faces diabólicas capazes de destruir a vida e a nação. Clamou-se pela guerra aos negros, aos quilombolas, aos índios, aos favelados, aos intelectuais, aos sem-terra, aos LGBTs, aos cultos de matriz africana e outros mais. Defendeu-se a punição exemplar (a eliminação pela morte virou lugar-comum) dos bandidos, dos favelados, dos imorais e pervertidos, dos comunistas, dos corruptos, dos progressistas, de todos aqueles vistos como ameaças à ordem (militarizada) da cidade, à família cristã e ao estado-nação ${ }^{6}$. 0 projeto político vencedor nas últimas eleições presidenciais foi elaborado consagrando como norte $o$ fazer $a$ guerra para defender um Estado-nação cristão. É dessa forte associação

6 Birman e Leite argumentam, com base na noção de metáfora da guerra, elaborada por Márcia Leite, como a temática da guerra e o apelo a forças militares se estabeleceu desde os anos 1980 no Rio de Janeiro. "À época (1980), a partir de um repertório discursivo, que ora se referia aos traficantes de drogas ilícitas, ora deslizava para assimilar seus moradores a esses, se justificava seu extermínio como estratégia de legítima defesa: precisava-se eliminar seus inimigos, os ditos bandidos que atacavam a cidade. 0 crime praticado por moradores de favelas e periferias, desde confundidos com bandidos, não poderia ser analisado simplesmente como um crime, mas sim através de um elo metafórico com o ataque que os bandidos faziam aos cidadãos de bem. Esses bandidos faziam uma guerra e as forças de segurança pública replicavam acionando a resposta necessária, fixando, assim, seu sentido através desse elo metafórico de todo crime como expressão de uma guerra [...]: cada crime supostamente relacionado ao tráfico de drogas seria, mais uma vez e cada vez mais, um assalto mortífero à cidade". Cf. BIRMAN, Patrícia; LEITE, Márcia Pereira. Rio e São Paulo: categorias emaranhadas e relativização dos seus sentidos nos estudos sobre (as chamadas) periferias. In: BARROS, Joana; COSTA, André Dal Boda da; RIZEK, Cibele (orgs.). Os limites da acumulação: movimentos e resistências nos territórios. São Carlos: IAU/USP, 2018. p. 29. Cf. também LEITE, Márcia Pereira. La favela et la ville: de la production des "marges" à Rio de Janeiro. Brésil: Sciences humaines et sociales, n. 3, p. 109-128, 2013. Disponível em: https://journals.openedition.org/ bresils/472. Acesso em: 6 ago. 2020. Cf. LEITE, Márcia Pereira. Entre o individualismo e a solidariedade: dilemas da cidadania e da política no Brasil. Revista Brasileira de Ciências Sociais, v. 15, n. 44, p. 73-90, 2000. Disponível em: https://doi.org/10.1590/ S0102-69092000000300004. Acesso em: 6 ago. 2020. 
entre guerra e religião que trataremos aqui, inspirando-nos na obra de Talal Asad, autor que reconfigurou os estudos da religião ao explorar os vínculos constitutivos desse campo de estudos com a modernidade secular.

\section{A partir de uma interrogação, um deslocamento}

Uma poderosa interrogação de Talal Asad nos sugeriu o fio desse texto. Disse ele: por que uma agressão em nome de Deus tem o poder de chocar as sensibilidades "liberais" enquanto a produção de mortes e da guerra é tão facilmente aceita? Asad faz essa pergunta por ocasião das controvérsias a respeito das charges publicadas contra o profeta Maomé e a fúria ameaçadora que provocou em seus fiéis mulçumanos ao redor do mundo?.

Rapidamente, ambas ganharam um peso estratégico na política global. O free speech foi acionado como um valor ocidental inquestionável, negado pelo Oriente. Buscou-se reinvestir, a partir do 11 de setembro, em uma diferença irredutível (nunca inteiramente abandonada) entre a civilização ocidental cristã e o oriente mulçumano ${ }^{8}$. Inaugurou-se um novo período de guerra fria ${ }^{9} \mathrm{e}$, paulatinamente, cristalizou-se um estado de guerra contínuo, alimentado por uma forte repulsa aos mulçumanos vistos como responsáveis pelo terrorismo no mundo, além de contrários aos valores fundantes das democracias ocidentais, como a liberdade

7 Essas charges, encaradas como pilhérias a princípio anódinas na França e nos países europeus, de modo geral, foram relacionadas ao terrorismo, principalmente após os ataques ao Charlie Hebdo, na França, que redimensionou o seu sentido diante das mortes que provocou.

8 A obra Orientalismo: o Oriente como invenção do Ocidente, de Edward Saïd, teve um papel precursor. Cf. SAIID, Edward W. Orientalismo: o Oriente como invenção do Ocidente. São Paulo: Companhia das Letras, 1978.

9 A respeito da guerra fria e dos usos de diferenças religiosas acionados novamente pelos EUA no combate ao "terrorismo", cf. SCOTT, Joan Wallach. Sex and Secularism. Princeton: Princeton University Press, 2018. 
de expressão e a autonomia individual ${ }^{10}$, já adotadas como valores cristãos ${ }^{11}$.

No entanto, a defesa dos valores ocidentais seculares, lembremos, significou também uma relação bastante controvertida com os chamados Direitos Humanos. Esses, que abstratamente garantem o direito à vida e à proteção de todo e qualquer indivíduo, passaram a ter, mais uma vez, no início desse século, o seu emprego condicionado pela ameaça que passou a representar a figura do terrorismo em expansão, proveniente do Islã. Desde o início do novo século, os estados-nações europeus e americanos mobilizaram o antigo antagonismo da cristandade ao Oriente mulçumano para reconstruir ativamente a defesa do Cristianismo como um pilar do Ocidente secular moderno, por intermédio de políticas neoliberais e neocoloniais. Vínculos entre guerra e religião, modernidade secular e Cristianismo, democracia e razão foram postos a serviço de imagens imperiais da cristandade e das suas relações de poder ${ }^{12}$. A violência da guerra sem limites, pela qual se corporificam novos sofrimentos por meio de dispositivos técnico-militares cada vez mais esmagadores é o saldo de todo dia no mundo globalizado, como já escreveu $A \operatorname{sad}^{13}$. 0 ataque armado a civis, o uso de armas químicas, o sequestro e aprisionamento

10 O uso do véu pelas mulheres mulçumanas transformou-se em um símbolo do caráter atrasado de sociedades teocráticas a serem derrotadas pelos movimentos de secularização dos estados-nação ocidentais. Para uma crítica desses pressupostos, cf. MAHMOOD, Saba. Politics of Piety: The Islamic Revival and the Feminist Subject. Princeton: Princeton University Press, 2012. Nesse livro, a autora discute as noções de agência, política, embodiment e ética para abordar os debates sobre religiosidade moderna e as relações de gênero.

11 SCOTT, Joan Wallach. Sex and Secularism. Princeton: Princeton University Press, 2018.

12 Sobre a constituição dos discursos e dispositivos político-jurídico-militares do terrorismo nos EUA e suas articulações no Brasil, cf. RABELO, Thiago Pereira. "Um seguro para a paz": ensaio sobre políticas de combate ao terrorismo, do PATRIOT Act norte-americano (2001) à Lei Antiterrorismo brasileira ( $\left.n^{\circ} 13.260 / 2016\right), 2019$. Dissertação (Mestrado em Ciências Sociais) - Programa de Pós-graduação em Ciências Sociais, Universidade Estadual do Rio de Janeiro, Rio de Janeiro, 2019.

13 ASAD, Talal. Formations of the Secular: Christianity, Islam, Modernity. Stanford: Stanford University Press, 2003. 
de indivíduos sob suspeita em zonas de "não direito", a multiplicação de campos de refugiados, as práticas de torturas, tudo isso, em suma, se impôs como uma defesa do Ocidente como civilização, lugar da modernidade racional e democrática, contra os inimigos definidos também como encarnação de um mal selvagem antagônico à cristandade.

Ao articular tópicos habitualmente dissociados em uma mesma questão, Asad abriu um caminho promissor para pensar o uso da violência tal como este se estrutura como uma prática justificada. Ao perguntar sobre as diferenças entre uma guerra em nome do Ocidente cristão e uma guerra em defesa de Maomé, ele nos reenvia para o horror da guerra em nome da religião ao mesmo tempo que destaca a nossa habitual complacência quando a guerra é realizada em nome do estado-nação ${ }^{14}$.

A interrogação de Asad visaria, pois, em primeiro lugar, questionar o lugar de violência atribuído aos mulçumanos "terroristas". Em segundo lugar, destacar como se naturalizaram certas formas de violência no Ocidente moderno. As imagens de guerra e destruição transmitidas incansavelmente pelas mídias não provocam horror nem rejeição, porém uma aceitação dessas como parte da ordem natural das coisas.

A afırmação do secular-ocidental-cristão em oposição ao religiosooriental-mulçumano, identificado como antidemocrático, primitivo e terrorista tem sido reiterada, lembremos, pela maioria dos dirigentes europeus e também americanos. Um "novo" antagonismo se desenha diante de um antigo e renovado inimigo da civilização, de certo modo transformando o lugar do religioso nos conflitos atuais. Scott destaca como o lugar da religião nas sociedades ocidentais modernas e secularizadas foi e é crucial, em tempos de guerra fria:

[...] o legado da guerra fria religiosa permanece em torno da "Guerra Global ao Terror". É apresentado como um desafio religioso extremista à legitimidade do sistema internacional moderno designado como

\footnotetext{
14 A força da sua retórica, sugere Judith Butler, origina-se: "de um sentido que é inaceitável responder com justa indignação às mortes causadas por aqueles que fazem a guerra em nome da religião e com complacência moral às mortes causadas por aqueles que fazem a guerra em nome do estado-nação". Cf. ASAD, Talal; BROWN, Wendy; BUTLER, Judith; MAHAMOOD, Saba. Is Critique Secular? Blasphemy, Injury and Free Speech. California: University of California Press, 2009. p. 108.
} 
EXILIUM 1 (2020)

separado e, ainda assim, "defensor da religião". A incorporação do cristão não apenas como uma dimensão, mas como a fonte do secular democrático foi um produto duradouro da Guerra Fria. No embate promovido pelo discurso da civilização, o Islã passou a ser retratado como uma forma excessiva de espiritualidade (um "desafio religioso extremista"), eclipsando a racionalidade herdada dos indivíduos - a racionalidade que era a fonte da consciência cristã interior e da liberdade que expressava - em nome de uma identidade coletiva imposta ${ }^{15}$.

O estatuto renovado do religioso a partir do 11 de setembro motivou Talal Asad em suas reflexões sobre a modernidade ocidental-cristã, não para afirmar mais uma perspectiva normativa, mas sim para refletir sobre os impensáveis embutidos em sua história. Analisar os seus sentidos, portanto, é voltar-se para certas configurações específicas no interior das quais o religioso é definido e participa do contexto em que se integra. Asad não teria visado, em sua obra, conhecer melhor o Islã, segundo afirma. Antes, buscou elaborar certas contraposições que o auxiliassem a desnaturalizar as percepções ocidentais modernas. Entre elas, destacase a sua crítica à premissa do religioso como um objeto universalmente existente e passível de ser reconhecido por si mesmo, como uma instância simbólica essencial da vida humana em sociedade ${ }^{16}$.

Analisar o religioso no interior de um campo de forças específico, o seu jogo de poderes e o acionamento de valores é, pois, essencial. Acompanhando Talal Asad, vamos sugerir algumas interpretações para compreender o enlace entre guerra e religião no Brasil, notadamente no Rio de Janeiro, cidade em que estou situada ${ }^{17}$.

15 SCOTT, Joan Wallach. Sex and Secularism. Princeton: Princeton University Press, 2018. p. 132-134.

16 Para conferir a discussão realizada por Asad sobre o famoso texto de Clifford Geertz a respeito da religião como categoria antropológica, cf. ASAD, Talal. Genealogies of Religion: Discipline and Power on Christianity and Islam. Baltimore: The Johns Hopkins University Press, 1993. p. 27-74.

17 David Scott sintetizou as questões básicas formuladas por Asad: "Asad se inclinou a começar por um complexo diferente de perguntas: quais são os pressupostos conceituais e ideológicos através dos quais o Ocidente moderno (e a antropologia, em particular) pensa a 'religião'? Qual é a história do poder através da qual esse modo de pensar foi estabelecido? E quais são as maneiras - conceituais, institucionais, 
GUERRA, RELIGIÃO, SECULARISMO E ALGUNS SUJEITOS SENSÍVEIS

\section{Na campanha, a ação dos homens}

A campanha eleitoral refletiu certamente uma circunstância específica que não nos autoriza a supor que esse momento corresponda à criação de uma maioria política conservadora estável. Alterou, no entanto, significativamente, um certo equilíbrio de poder. Muitas especulações sobre outros resultados possíveis foram aventadas. 0 que nos interessa aqui, no entanto, é compreender certas decorrências que parecem cristalizar um potencial mais efetivo de novos procedimentos políticoreligiosos $^{18}$. É preciso, por um lado, entender os dispositivos morais e

ideológicas - pelas quais a compreensão ocidental moderna da religião alterou materialmente os modos de vida das pessoas? Como esta foi conquistada e passou a dominar? São essas as questões levantadas sobre os problemas da formação dos objetos de investigação antropológica. Como a antropologia (e o Ocidente moderno do qual a antropologia é parte integrante) faz seu objeto disciplinar ("religião", digamos) ter consequências sobre como se nomeiam, se descrevem e se analisam os discursos e as práticas que encontra no mundo não europeu". Cf. ASAD, Talal. Responses. In: SCOTT, David; HIRSCHKIND, Charles (orgs.). Powers of the Secular Modern: Talal Asad and His Interlocutors. Stanford: Stanford University Press, 2006. p. 139.

18 As obras sobre as igrejas evangélicas hoje se contam às centenas. Não vou me referir a elas a não ser a algumas que me interessaram, porque se mostraram particularmente focadas na laicidade no Brasil e nas mudanças conservadoras provocadas pelos evangélicos, associadas às formas de ação política e eleitoral. Cf. MARIANO, Ricardo. Laicidade à brasileira: católicos, pentecostais e laicos em disputa na esfera pública. Civitas, Porto Alegre, v. 11, n. 2, p. 238-258, 2011. Disponível em: https://doi.org/10.15448/1984-7289.2011.2.9647. Acesso em: 6 ago. 2020. Cf. também: QUADROS, Marcos Paulo Reis; MADEIRA, Rafael Machado. Fim da direita envergonhada? Atuação da bancada evangélica e da bancada da bala e os caminhos da representação do conservadorismo no Brasil. Opinião Pública, Campinas, v. 24, p. 486-522, 2018. Disponível em: https://doi.org/10.1590/1807-01912018243486. Acesso em: 6 ago. 2020.; FONSECA, Alexandre Brasil. Discursos evangélicos de uma Nova Direita à brasileira. In: SOLANO, Ester (org.). Brasil em colapso. São Paulo: Ed. Unifesp, 2019.; BURITY, Joanildo. A onda conservadora na política brasileira traz o fundamentalismo ao poder? In: ALMEIDA, Ronaldo; TONIOL, Rodrigo (org.). Conservadorismos, fascismos e fundamentalismos: análises conjunturais. Campinas: Ed. da Unicamp, 2018. p. 15-66.; MIRANDA, Júlia. Estado laico no Brasil: entre sofismas e ambiguidades. Cultura y Religión, Santiago de Chile, v. 7, n. 2, p. 69-85, 2013.; ALMEIDA, Ronaldo. A onda quebrada: evangélicos e conservadorismo. 
religiosos utilizados nesse processo, em certa medida secular e, por outro lado, perceber como esses, ao mesmo tempo visibilizam e revelam certos fios que os ligam ao passado da formação do estado-nação brasileiro como escravocrata e colonial, como católico e secular. Uma vez que esse passado diz respeito a um tempo mais extenso e (ainda presente), é interessante considerar o quanto o par guerra e religião se encontra na experiência atual de certos segmentos sociais e na formação de suas subjetividades.

Como nos referimos anteriormente, a campanha vencedora de Jair Bolsonaro realizou algo nunca visto em uma disputa eleitoral para a Presidência da República: uma exaltação ímpar de comportamentos violentos. Com efeito, vimos, de espanto em espanto, aparecer nas mais diversas mídias falas que continham ameaças de morte, insultos, ataques físicos e morais aos que passaram a representar os inimigos combatidos. Guerra aos bandidos, guerra aos comunistas, aos corruptos, guerra a tudo isso que está aí fez da campanha um elogio infınito da destruição mortífera como meio de salvar a nação. Mas esse elogio ganhou eficácia na medida em que conseguiu encarnar certas formas de interação social presentes entre nós e oferecer um horizonte de redenção a ser alcançado pela guerra e pela religião.

Destaquemos a elaboração de um repertório de gestos, corpos e imagens gramaticalmente associados à violência masculina, ao mesmo tempo conhecida e renovada. 0 agente dessa violência, sujeito desses enunciados, se confunde com a figura do homem "sem cor" e hétero, isto é, aquele cuja branquitude é dada porque ele se define como antagônico aos que são atacados: negros, indígenas, quilombolas, gays, mulheres,

Cadernos PAGU, São Paulo, v. 50, p. 5-30, 2017. Disponível em: https://doi.org/ 10.1590/18094449201700500001. Acesso em: 6 ago. 2020.; CAMURÇA, Marcelo. Religião, política e espaço público no Brasil: perspectiva histórico/sociológica e a conjuntura das eleições presidenciais de 2018. Estudos de Sociologia, Recife, v. 2 , n. 25,2019 . Disponível em: https://periodicos.ufpe.br/revistas/revsocio/article/ view/243765/34005. Acesso em: 6 ago. 2020.

Bem como Miranda e Oro relacionam preocupações políticas e eleitorais com o debate sobre laicidade no Brasil, cf. ORO, Ari Pedro. A laicidade no Brasil e no Ocidente. Algumas considerações. Civitas, Porto Alegre, v. 11, n. 2, p. 221-237, 2011. Disponível em: https://doi.org/10.15448/1984-7289.2011.2.9646. Acesso em: 6 ago. 2020. 
feministas, nordestinos, pobres, favelados e outros mais. Não será esse o modelo do indivíduo/cidadão, ao mesmo tempo conhecido e naturalizado, para construir em novas bases o estado-nação? Essa figura masculina tida como universalmente capaz de encarnar a legitimidade do uso da força ganhou um estatuto renovado ${ }^{19}$. Trata-se de uma figura masculina que pode se autonomear e também designar os inimigos da nação e os alvos de seu repertório de ataques verbais e corporais. Figura governamental também justificada como um poder patriarcal.

Mas seria falso considerarmos que a elaboração desse repertório de gestos prescindiu de relações sociais específicas que as impulsionaram. Um vínculo interno à pessoa é necessário para promover a obediência, afirma Asad, referindo-se à autoridade religiosa e a qualquer outra, como supomos:

O que me interessa, no entanto, é a autoridade como um elo interior, algo que eu sustento e que não pode ser explicado pela ciência da linguística - por intermédio da análise da autocitação ou da linguagem de comando, por exemplo. Um encontro, não uma comunicação, encontra-se no coração da autoridade... Eu digo que, se desejamos analisar a autoridade na tradição cristã ou islâmica, não devemos lidar com esta como pura textualidade - como signos a serem lidos e interpretados. É claro que devemos prestar atenção à linguagem aqui, mas a linguagem enraizada em um complexo somático (ouvir-sentirver-lembrar) entranhado nas pessoas fazendo / refazendo a si próprias ou a outras ao longo do tempo ${ }^{20}$.

O discurso seria também um processo "somático": impossível separar o símbolo, o físico e o mental do poder. Poder, nesse sentido, continua Asad: "Sentir, lembrar e esperançar-se são eventos tanto físicos quanto mentais. Quando menciono a separação entre símbolo e poder

19 Cf. DAS, Veena. Fronteiras, violência e o trabalho do tempo: alguns temas wittgensteinianos. Revista Brasileira de Ciências Sociais, Rio de Janeiro: Nova Fronteira/Faperj, v. 14, n. 40, p. 31-42, 1999. Disponível em: https://doi.org/10.1590/ S0102-69091999000200003. Acesso em: 6 ago. 2020.

20 ASAD, Talal. Responses. In: SCOTT, David; HIRSCHKIND, Charles (orgs.). Powers of the Secular Modern: Talal Asad and His Interlocutors. Stanford: Stanford University Press, 2006. p. 212. 
tenho em mente a diferença entre ser informado e prestar atenção, entre uma simples interação e uma chamada combinatória"21.

Ameaçar adversários, insultá-los e agredi-los fisicamente, com efeito, me parece que foi a afırmação reiterada na esfera pública de um sujeito/cidadão renovado cujas raízes sociais são mais profundas do que o tempo eleitoral permite compreender. Não é necessário remontar à escravidão para reconhecer o quanto a legitimidade do poder se ancora na obediência e no reconhecimento de figuras como essas, cujo exemplo maior atual é o do Presidente da República - liberado dos limites sempre dúbios associados à condição de homem/macho/heterossexual/branco, com uma posição de classe e de estatuto diferenciados em relação a maioria da população de negros, pobres, mestiços, gays e periféricos pela raça, pela classe e pelo gênero. Armar os "homens de bem", os cidadãos, os homens de família, os proprietários, os religiosos é um dos lemas do governo eleito que nos convida a reatualizar experiências nunca substancialmente abolidas, relativas à dominação de gênero, raça e classe na formação do estado-nação brasileiro ${ }^{22}$.

Desse modo, o repertório e a gramática da exclusão e destruição dos inimigos têm alimentado a atualização de experiências de um modelo masculino de homem cujo exercício da violência física e verbal parece ter sido sempre assegurado pelo estado secular e seus entrelaçamentos religiosos. Vejamos agora como operaram as distinções de gênero e as referências religiosas nesse período.

21 Ibidem, p. 213.

22 O projeto de liberação do porte de armas apresentado pelo governo foi seguido de um outro projeto jurídico, "o excludente de ilicitude" que dispensa de julgamento os agentes da lei que cometem homicídios nos territórios habitados pelos supostos "bandidos", isto é, as favelas e periferias. Embora o excludente de ilicitude tenha sido retirado do processo jurídico pelo Congresso Nacional, diminuiu significativamente o controle judicial sobre as práticas mortíferas da polícia. $O$ atual governador do Rio de Janeiro promove, cotidianamente, o ataque armado da polícia aos moradores das favelas e periferias. 0 presidente da república assinou um indulto de Natal a policiais acusados de crime de morte. E houve também um aumento exponencial do porte de armas pela população, incentivado pelo governo, que diminuiu as exigências legais para obtê-lo. 


\section{Relações de gênero e a potência da profanação}

Como a violência mortífera e o chamado à guerra se associou ao sexo, à escatologia, à religião e à morte e ganhou autoridade sobre corpos e mentes? Assinalamos que as fake news tiveram um efeito importante, posto que fizeram das eleições uma questão relacionada a vida como moralmente digna de ser vivida, em oposição às formas ameaçadoras de profanação e devastação veiculadas.

Com efeito, as fake news muitas vezes se construíram por meio de referências escatológicas, chamados à guerra e ataques aos corpos das mulheres e às suas funções reprodutivas (o kit gay para crianças, as mamadeiras de piroca, imagens de pedofilia associadas aos adversários políticos). Imagens e dizeres morais e religiosos ultrajantes, paralelos aos chamados à guerra, foram abundantes. Construíram, assim, o modelo cristão tradicional de mulher pela negação do que seria o seu oposto, acionado como ofensa, como um desrespeito aos valores básicos considerados acima da política. Se é impossível separar a moral da política, como seria aceitável compor com adversários que destruíam a base moral da vida a ser vivida? Em outras palavras, de que maneira reconhecer como humanos aqueles que agem sem aceitar a humanidade dos outros? Forjou-se uma dicotomia entre humanos e não humanos por meio do uso das fake news replicadas pelos grupos de apoio da campanha e silenciadas em seus efeitos perversos pela mídia hegemônica. 0 objetivo dos inimigos da extrema-direita, fartamente proclamados, seria, como foi dito e repetido, destruir a família, as mulheres/mães, portanto a vida humana digna e passível de ser vivida. Constituiu-se um discurso de autoridade através do qual o ataque aos profanadores, mais do que aceito, passou a ser desejado. Foram apontados como autores desses ataques "a esquerda", "os progressistas", "o PT" e "os comunistas".

Os efeitos das fake news estão fortemente associados à produção de verdades com um alto poder de convencimento cujos elos com experiências sensoriais e corporais foram particularmente explorados. Ou seja, não se tratou, no caso das fake news, de simples processos interpretativos, de uma "leitura" dos signos da realidade, de uma "representação" do real, entre outras formas existentes em um espaço público aberto a divergências, mas sim de processos de transformação 
das pessoas que são subjetivamente mobilizadas e que dessa maneira descobrem subjetiva e objetivamente a verdade transformadora, que se inscreve tanto na mente quanto no corpo. Retomemos, pois, um dos argumentos de Asad:

Se pensarmos no relacionamento de autoridade como a capacidade de alguém em compreender e obedecer a uma verdade convincente, 0 que importa não é o sujeito que interpreta os signos dados, mas que ele se conecte à "verdade" do que lhe é apresentado como aparente e, assim, como sujeito passa a ser capaz de transformar a si próprio neste momento. É este momento - prolongado pela lembrança e pelo desejo - que o submete à sua autoridade, transformando-o. É o que marca o início. Passa a se impressionar com o que não havia notado antes, a se impressionar com uma "nova presença" que opera para se tornar uma parte espontânea de si mesmo. Como alguém apaixonado, vive em uma verdade arrebatadora, passa a habitar um relacionamento com alguém que é ao mesmo tempo interno e externo ${ }^{23}$.

As fake news, pelas formas de divulgação (centradas em redes de confiança) e pelos temas de quais trataram, alimentaram nos sujeitos desejos de mudanças e uma participação intensa em debates levados adiante em todas as esferas da vida. Passou-se a discutir eleições nas famílias, entre amigos, estranhos e conhecidos. Exprimiu-se ódio, amor, inimizade, entusiasmo, indignação e raiva. Um campo disruptivo emergiu como nunca dantes. Viu-se o quanto a moralidade, nesse momento, transformou-se em um divisor de águas e a potência dela ultrapassou em muito o campo limitado da política, em que habitualmente, pensávamos, esta se encontrava alocada. Explodiu, digamos, a divisão moderna e secular entre as esferas ${ }^{24}$. Ao menos nesse momento da vida social, senão

23 ASAD, Talal. Responses. In: SCOTT, David; HIRSCHKIND, Charles (orgs.). Powers of the Secular Modern: Talal Asad and His Interlocutors. Stanford: Stanford University Press, 2006. p. 213.

${ }^{24}$ Casanova aponta para a separação entre domínios como o critério mais importante para definir o secular. A noção de religião pública que ele desenvolveu foi amplamente discutida entre nós e mostrou-se particularmente útil para compreender a especificidade da formação do estado-nação brasileiro (Cf. CAMURÇA, Marcelo. Religião, política e espaço público no Brasil: perspectiva histórico/sociológica e a conjuntura das eleições presidenciais de 2018. Estudos de Sociologia, Recife, 
nas concepções sociológicas correntes, a vida sujeita a processos de profanação e morte ganhou espaço no debate.

Lembremos que fake news foram elaboradas essencialmente como um ataque às famílias e, em especial, às mulheres. Vejamos, então, como os efeitos de verdade que produziram estão relacionados a experiências de vida visceralmente constituídas por intermédio da presença feminina e católica na elaboração política e religiosa da nação, desde seus primórdios ${ }^{25}$. Com efeito, as notícias que tiveram maior impacto foram majoritariamente imagens de violação do corpo feminino. Ao lado desse tema, os chamados ao combate armado, à eliminação dos inimigos para

v. 2, n. 25, 2019. Disponível em: https://periodicos.ufpe.br/revistas/revsocio/article/ view/243765/34005. Acesso em: 6 ago. 2020. Ver também: MONTERO, Paula. Religião cívica, religião civil, religião pública: continuidades e descontinuidades. Debates do NER, Porto Alegre, v. 1, n. 33, p. 15-39, 2018. Disponível em: https://doi. org/10.22456/1982-8136.88037. Acesso em: 6 ago. 2020.). Algumas configurações particulares dos entrelaçamentos entre o religioso e outros campos foram desenvolvidas por Pierruci, Mariano, Oro, Burity, Giumbelli, Machado, Birman, Vital, entre muitos outros. Asad chama a atenção para a necessidade de valorizar os processos que engendraram o "religioso" e também as diferenças em cada estadonação, dado que seus entrelaçamentos e disputas são específicos. Cf. o debate entre Casanova e Asad em: CASANOVA, José. Secularism Revisite: A Reply to Talal Asad. In: Scott, David; HIRSCHKIND, Charles. Powers of the Secular Modern: Talal Asad and His Interlocutors. Stanford: Stanford University Press, 2006.

250 crescimento da participação política das igrejas evangélicas foi seguido de perto pelo ativismo da igreja católica nesses novos tempos, em defesa da mesma pauta moral promovida mais abertamente pelas igrejas evangélicas. Segundo Sales e Mariano (2019, p. 13): "O ativismo católico em defesa dos Direitos Humanos tem seu ponto de inflexão diante dos direitos sexuais e reprodutivos. A Igreja opõe-se à expansão desses direitos e 'bate de frente' com os movimentos feministas e LGBTs que os reivindicam. Vide a proposta da CNBB de inserir a frase 'defesa da vida desde a concepção' no texto constitucional, visando impedir a realização do aborto em qualquer situação (Dalmolin, 2011; Rocha, 2005), o que representaria um retrocesso mesmo em relação à legislação anterior, que previa o aborto legal apenas nos casos de estupro e de risco de vida da mãe. Posteriormente, entidades pastorais e CNBB reforçaram seu ativismo nessa área, aliando-se a ativistas, movimentos e redes internacionais antiaborto em defesa da 'vida desde a concepção' (Rezende, 2016)". É preciso lembrar, no entanto, que o feminino para a formação da subjetividade católica se faz pela sacralização da mulher que tem a Virgem Maria como referência. 0 culto à Maria é também um culto nacional. 


\section{alcançar a redenção do país. Reportagens que vinculavam os candidatos progressistas a gestos ultrajantes à moral e à integridade corporal das pessoas foram abundantes ${ }^{26}$.}

26 Embora ridicularizados pelos setores seculares no espaço público, o uso dessas imagens de profanação do corpo e da vida continuaram no período pós-eleitoral. Chamou a atenção da mídia nacional e internacional um discurso da ministra que representa o Ministério da Mulher, da Família e dos Direitos Humanos: "A nova ministra brasileira da Mulher, Família e Direitos Humanos, Damares Alves, tem ideias especiais sobre a Holanda. Em um discurso de 2013, a ministra afirma que especialistas holandeses dizem que 'um menino a partir dos sete meses de idade deve estar sexualmente satisfeito, para que ele possa ser um homem sexualmente saudável quando adulto'. Segundo a ministra, o mesmo conselho se aplica às meninas. 'Especialistas' da Holanda estariam recomendando que "a vagina de uma menina deve ser estimulada desde cedo para que ela possa sentir prazer quando adulta'. [...]". NOGUEIRA, Kiko. "Ministra brasileira conta fábulas sexuais sobre a Holanda": maiores jornais holandeses denunciam fake news de Damares. DCM, 24 jan. 2019. Disponível em: https://www.diariodocentrodomundo.com.br/ministra-brasileira-conta-fabulassexuais-sobre-a-holanda-maiores-jornais-holandeses-denunciam-fake-newsde-damares/. Acesso em: 6 ago. 2020. A acusação quase cotidiana aos partidos à esquerda de planejarem ataques à integridade física e moral da família, principalmente da mulher, dominou para além da campanha eleitoral. Imediatamente após as eleições, o presidente postou um vídeo considerado impróprio para uma exibição pública: "Postado pelo presidente da República no Twitter em 5 de março, o vídeo que mostrava duas pessoas dançando em cima de um ponto de táxi durante a passagem de um bloco de Carnaval em São Paulo. Nas imagens, elas praticam atos obscenos, incluindo uma cena em que um urina no outro - prática fetichista conhecida como 'golden shower'. Junto às imagens, Bolsonaro escreveu: 'Não me sinto confortável em mostrar, mas temos que expor a verdade para a população ter conhecimento e sempre tomar suas prioridades. É isto que tem virado muitos blocos de rua no carnaval brasileiro. Comentem e tirem suas conclusões (sic)'... A publicação do vídeo gerou controvérsia imediata, com milhares de pessoas criticando o que consideraram 'falta de decoro', postagem de imagens escatológicas que não representam o Carnaval e uma tentativa de desviar a atenção dos protestos de foliões contra o presidente nos blocos de rua. Apoiadores do presidente, por sua vez, defenderam o uso do vídeo para fazer o que consideram uma denúncia. Para a deputada Joice Hasselmann (PSL-SP), por exemplo, o vídeo teria exposto a hipocrisia de parte da esquerda. 'Essa esquerda que mostra bundas e peitos nas ruas, que usa símbolos religiosos pra cometer atos profanos em praça pública, que apoia exposições com adultos pelados para crianças tocarem, agora está 'chocada' com o vídeo compartilhado pelo presidente', escreveu a política, atual líder do governo no Congresso." 
O caráter visceral da ruptura que muitos eleitores e, particularmente, eleitoras passaram a exprimir nos leva a refletir sobre o corpo e sobre a violência generificados. De um lado, vimos acontecer ataques na forma de imagens que revelariam uma inaceitável profanação de corpos femininos que exprimiam verdades sacralizadas religiosamente, associadas ao valor concedido à família e ao papel da mulher. E, de outro, a exaltação do combate armado, da força física e dos insultos como forma de existir e agir dos homens viris, brancos e heterossexuais. A novidade desses novos tempos reside também nas diferenças entre a ação católica e a evangélica. Enquanto os católicos voltaram-se para "promover a vida" e defender a mulher santificada ${ }^{27}$, subsumindo à nação a proteção da Virgem, tendo $\mathrm{N}$. S. Aparecida como madrinha do Brasil, os evangélicos incluíram a "guerra santa" como uma obrigação religiosa para transformar a nação. Desse ponto de vista, estes últimos uniram religião e política de modo a justificar e autorizar a prática da guerra para a construção de uma nação renovada. A "limpeza moral" promovida pelos justos e homens de bem integra esse projeto que estabelece a cidadania como um direito condicionado pela ordem cristã patriarcal, em que os homens podem ser chamados a morrer pela nação e as mulheres a garantir a reprodução digna da vida.

É interessante como Veena Das discute com Talal Asad as premissas hobbesianas do contrato social moderno para sugerir que esse pode ser mais bem compreendido como um contrato também sexual. Isso porque:

[...] a reprodução feminina é vista como corretamente pertencendo ao estado de tal forma que como cidadãs são obrigadas a se encarregarem de crianças legítimas que estarão, por sua vez, prontas para morrer pela

27 Chama a atenção para o lugar da mulher atribuído pelo catolicismo na formação da nação. Um exemplo significativo é a instituição da N. S. Aparecida como padroeira do Brasil. Cecília Mariz (2003) e Marjo Theijo (2003) trabalharam o modelo católico da mulher associado ao sacrifício e ao sofrimento. Mas, como chama atenção Adriana Vianna, o sofrimento das mulheres é também uma forma de agência. A profanação das mulheres por meio de imagens não as desqualifica, ao contrário, reforça a agência dessas no interior do contrato social como contrato sexual (apud DAS, 2006). Cf. THEIJE, Marjo; JACOBS, Els. Gênero e aparições marianas no Brasil contemporâneo. In: STEIL, Carlos Alberto; MARIZ, Cecília; REESINK, Misia (orgs.). Maria entre os vivos: reflexões teóricas e etnografias sobre aparições marianas no Brasil. Porto Alegre: Ed. da UFRGS, 2003. p. 269-282. 
nação. Assim, sexo e morte, reprodução e guerra, vieram a ser parte da mesma configuração de ideias e instituições através das quais o estado-nação estabelece defesas para evitar a incertitude que emana dos perigosos aliens e das devastações do tempo ${ }^{28}$.

Forjou-se um plano discursivo em que as oposições políticas na esfera pública estariam subsumidas às discussões que efetivamente importavam, a saber, àquelas que defendiam a vida moralmente correta e digna de ser vivida e o combate militar a todas as formas de profanação de seus pressupostos cristãos. Tudo o mais perderia seu apelo. Lembremos que as discussões correntes no espaço público têm obedecido a uma clivagem importante: a linguagem "da política" centrada sobre os debates parlamentares e interesses econômicos da elite do país - debates que, para grande parcela da população, são percebidos como abstratos e distantes dos problemas que enfrentam de fato. As categorias da "grande política" empregadas no cotidiano são abstratas e parecem não se aplicar a essas experiências de vida em regimes específicos de exceção, onde vivem os que são submetidos a toda sorte de dificuldades associadas aos lugares em que vivem, à cor, ao gênero e à classe que os identificam ${ }^{29}$.

Recusou-se o diálogo no plano da política tal como esse tem sido, há longo tempo, inscrito como próprio dessa esfera, a saber, racional e universal porque abstrato no campo das promessas vãs, sempre repetidas. 0 ataque devastador aos valores cristãos da vida adquiriu um sentido radical de mudança raramente alcançado. Como chamou a atenção Asad, a blasfêmia propõe uma ruptura radical, como um ataque inaceitável aos valores mais caros daqueles que a sofrem. E exige uma resposta igualmente radical: a promessa de eliminar/excluir aqueles que a promovem, no nosso caso, os comunistas, os corruptos e os bandidos.

28 DAS, Veena. Violence, Gender, and Subjectivity. Annual Review of Anthropology, v. 37, 2008. p. 285.

29 No entanto, vemos o recurso às categorias relacionadas à cidadania, aos direitos humanos e à defesa das populações por parte de muitos militantes de vários movimentos e, em momentos de mobilização política, como foi o caso do assassinato da vereadora Marielle e também o caso do assassinato e tortura do Amarildo, pedreiro e morador de favela, as categorias relacionadas a direitos ganham uma nova potência e são acionadas com um sentido mais abrangente. 
Atribuir autoridade aos evangélicos tem sido também uma maneira de combater os inimigos da vida como inimigos de Deus e da nação. A associação entre a defesa da vida e a promoção da guerra se estruturou pela ênfase na dimensão moral requerida pela distinção entre os gêneros. Mas também se estruturou porque ofereceu um novo horizonte por meio da associação entre guerra e religião, a saber, uma cidadania a ser alcançada pela ruptura com o crime e com a violência por meio da adesão religiosa e a prática dos horizontes morais e identitários que essa oferece ${ }^{30}$. Em outro texto, defendo que "a lógica da guerra, em suma, fortalece essa articulação essencialista dos gêneros [...]. Como se houvesse um consenso difuso e amplamente partilhado sobre a superioridade moral das mulheres em relação à violência e ao crime que abrange tanto pontos de vista religiosos como seculares"31.

A experiência de uma parte significativa de eleitores(as) deu lugar a uma nova compreensão das relações sociais e da participação política. Uma experiência coletiva que engendrou protagonismos e clivagens que nos desafiam exatamente porque foram elaborados também por intermédio de fortes experiências sensórias e corporais relacionadas à diferença de gênero para a renovação e redenção do país. A esfera pública não é um lugar de trocas racionais em uma linguagem secular e universal ${ }^{32}$. Como muitos autores já afırmaram, as linguagens sensórias são fundamentais no espaço público. Asad, com razão, criticou a perspectiva analítica que separa a aquisição de sentidos por meio da experiência corporal daquela que se realizaria unicamente por intermédio da experiência verbal.

30 BIRMAN, Patrícia; MACHADO, Carly. A violência dos justos: evangélicos, mídia e periferias da metrópole. Revista Brasileira de Ciências Sociais, v. 27, n. 80, p. 55-69, 2012. Disponível em: https://doi.org/10.1590/S0102-69092012000300004. Acesso em: 6 ago. 2020.

31 BIRMAN, Patrícia. Narrativas seculares e religiosas sobre a violência: as fronteiras do humano no governo dos pobres. Sociologia \& Antropologia, v. 9, n. 1, p. 111-134, 2019. Disponível em: https://doi.org/10.1590/2238-38752019v915. Acesso em: 6 ago. 2020.

32 Cf. HIRSCHKIND, Charles. Existe um corpo secular? Religião e Sociedade, v. 37, n. 1, p. 175-189,2017. Disponívelem:https://doi.org/10.1590/0100-85872017v37n1 cap10. Acesso em: 6 ago. 2020. 0 autor discute o que seria o secular em relação ao corpo. 
Justamente, inclusive, não considera que os discursos incidem sobre o corpo a partir de um lugar externo, ao contrário, o interno e o externo se constituem subjetiva e corporalmente nos processos interativos. Como afirmou, em uma frase: "Minha preocupação é com a maneira como o corpo vivo se submete através de imagens, práticas, instituições, programas, objetos - e através de outros corpos vivos" ${ }^{\prime 3}$.

0 "corpo vivo" como objeto e sujeito se fizeram presentes na campanha eleitoral em grande medida pelas fake news em uma dupla oposição a comportamentos no espaço público: aqueles que privilegiam a fala e o suposto da racionalidade e universalidade de suas promessas, em primeiro lugar, e, em segundo lugar, aqueles que ignoram os valores diferenciais baseados na experiência de vida dos atores considerados periféricos, que vivem nos lugares em que a guerra, a morte e a religião estão há longo tempo associadas ${ }^{34}$.

33 ASAD, Talal. Responses. In: SCOTT, David; HIRSCHKIND, Charles (orgs.). Powers of the Secular Modern: Talal Asad and His Interlocutors. Stanford: Stanford University Press, 2006. p. 214.

34 A noção de progresso que alimenta a narrativa secularista como uma conquista civilizatória costuma ignorar o lugar da guerra e da religião entre os seus princípios. Recuperar essa presença deve nos permitir analisar melhor os entrelaçamentos contemporâneos que estamos vivendo por meio de um governo de extrema-direita. Permito-me citar, em um artigo recente, o argumento que analiso aqui: "A narrativa secularista, conforme aponta Hirshkind (2017), sempre se confundiu com o processo de modernização do mundo a partir do Ocidente. Foi essa perspectiva civilizatória que construiu as colônias, o tratamento de suas populações dentro e fora das metrópoles europeias e justificou a escravidão além-mar.

Acompanhemos então as reflexões de Asad (2011) no texto em que associa a discussão do secularismo pelo viés dos sentidos modernos atribuídos ao sofrimento, abordando a crueldade e a tortura. Com efeito, o autor enfatiza o modo como a narrativa da modernidade secular fez da produção do sofrimento algo pouco compatível com a civilização: essa teria perdido a legitimidade desfrutada em épocas pregressas. No entanto, como observa, 'a história moderna da 'tortura' não é somente um registro da progressiva proibição de práticas cruéis, desumanas e degradantes. É também parte de uma narrativa secular de como alguém se torna verdadeiramente humano' (Asad, 2011: 174).

[...]

As reflexões do autor vão no sentido de apontar não somente um amortecimento do que se sente em relação aos atos cruéis, mas também um modo cada vez mais 
GUERRA, RELIGIÃO, SECULARISMO E ALGUNS SUJEITOS SENSÍVEIS

\section{E a liberdade de expressão?}

Assistimos, perplexos, à troca de insultos e à proliferação de ameaças que marcaram as eleições. E vimos, também, os defensores da pena de morte, da tortura, do extermínio dos adversários/inimigos defenderem a liberdade de expressão. 0 livre ofender como liberdade de expressão se naturalizou mais do que nunca.

Asad observou o quanto a ideia de liberdade de expressão pôde ser acionada politicamente para atacar os mulçumanos e defender a guerra fria promovida pelas sociedades ocidentais. Não precisamos, aqui, repetir o argumento da blasfêmia considerando o que representa para os mulçumanos uma figuração humana de Maomé, por exemplo.

Os casos francês e dinamarquês das caricaturas de Maomé, destacados por Asad, mostraram a necessidade de discutir democracia em relação à liberdade de fala na esfera pública: como pensar sobre os embates entre diferenças, pluralidade de culturas e de antagonismos quando uma ofensa inaceitável para uns seria considerada um princípio essencial a ser defendido por outros ${ }^{35}$ ? Quais seriam os limites do pluralismo? 0 direito de fazer caricaturas faz parte dos estados democráticos de modernos e seculares, o que deve ser aceito por todos, religiosos ou não, que queiram neles viver. Embora, argumente Talal Asad, a recíproca não seja

complacente e relativista de encarar esses usos da força bruta quando estão em jogo razões políticas e jurídicas. As doutrinas securitárias correntes, nesse sentido, construíram paulatinamente critérios sobre o uso de medidas cruéis, como a tortura (raramente nomeada como tal) ou medidas extremas (como o extermínio de populações civis), e assim indicam os limites razoáveis para sua aplicação: à medida que se atenham aos objetivos a alcançar, sempre maleáveis, aliás, equilibram-se os benefícios com os efeitos destrutivos também gerados". Cf. BIRMAN, Patrícia. Narrativas seculares e religiosas sobre a violência: as fronteiras do humano no governo dos pobres. Sociologia \& Antropologia, v. 9, n. 1, p. 111-134, 2019. Disponível em: https://doi.org/10.1590/2238-38752019v915. Acesso em: 6 ago. 2020.

35 Cf. ASSAD, Talal. Responses. In: SCOTT, David; HIRSCHKIND, Charles (orgs.). Powers of the Secular Modern: Talal Asad and His Interlocutors. Stanford: Stanford University Press, 2006.; CONNOLY, William. The ethos of pluralization. Minneapolis: University of Minnesota Press, 1995.; CONNOLY, William. Europe, a Minor Tradition. In: SCOTT, David; HIRSCHKIND, Charles (orgs.). Powers of Secular Modern: Talal Asad and His Interlocutors. Stanford: Stanford University Press, 2006. 
verdadeira. $O$ desrespeito a certos símbolos dos estados-nação é sujeito a penalidades diversas nas nações ocidentais. A discussão sobre a liberdade de expressão no Ocidente moderno ganhou um caráter político específico, associado às relações de poder que atravessam as relações sociais: o estatuto secular dessas sociedades tem sido acionado politicamente, já que inaugurou um novo período de guerra fria. É nesse contexto particular que se insiste em equacionar a religião mulçumana com o terrorismo, a selvageria e a ameaça ao Ocidente.

O meu propósito foi de recuperar rapidamente essa discussão para o nosso caso eleitoral no qual a bandeira da liberdade de expressão propiciou o suposto direito a falas racistas, misóginas, além de insultos de todos os tipos aos opositores da extrema-direita. Em nome dessas verdades enunciadas nas mídias sociais, defendeu-se a moralidade cristã e a prática da guerra como princípios acima daqueles constitucionais e legais.

A liberdade de expressão, como vemos, tem corpo e está associada a sensibilidades e a formas de interação diversas, articulando práticas discursivas de todas as naturezas. Não quero, no entanto, deixar no ar uma questão complexa e contraditória em relação aos horizontes do progresso afırmados como seculares. Termino, então, com uma última referência a Asad.

Não haveria, diz ele, no combate aos mulçumanos (pouco ou nada seculares), a defesa da liberdade de expressão - o que está em jogo seria algo muito além disso: um poderoso sentimento negativo, alimentado por diferenças de classe, raça e posição por parte dos mais bem situados. Um menosprezo por certas formas incultas das classes populares, de origem árabe (e africanas), se fazerem presentes nos centros europeus e também americanos.

O que não é muito diferente entre nós. 0 suposto "direito" de ofender as pessoas, tradicionalmente, depende, no Brasil, do estatuto social da vítima. A liberdade de expressão operou principalmente como liberdade de insultar e ameaçar. Vimos, nesse período recente, como insultar e ameaçar ganharam um novo alcance, banalizaram-se como um discurso autorizado pelas mais altas esferas do poder em relação a grupos sociais que até então não poderiam ser objeto de insultos. Integraram-se como novo modo de fazer a política e governar a cidade. Guerra corporal e 
verbal que se traduziram em propostas de governo nas quais é possível abater justificadamente os inimigos - tidos como violentos, destruidores, selvagens e bandidos -, que são incomparavelmente distintos dos homens de bem, pela cor e gênero defendidos enquanto valores patriarcais e coloniais.

Quais os limites e as fronteiras que devemos, a partir de agora, discutir, diante da oposição entre o secular e o religioso, se os encararmos principalmente através de seus entrelaçamentos? Ignorá-los seria cultivar uma bolha (onde estariam os modernos), que, de certo modo, não leva em conta os muitos fios que se entrelaçam no processo de fazer a religião, o estado e a política em suas configurações e dispositivos de poder, amplamente relacionados.

Não há volta ao ideário democrático construído através dos princípios liberais que hoje vemos nostalgicamente habitar as ilusões do capitalismo no passado. Não se trata de descrer na democracia como horizonte, mas de refletir sobre as ilusões relativas às garantias que estariam supostamente oferecidas pela construção de uma esfera pública racional cuja linguagem seria perfeitamente capaz de incluir, como protagonistas legítimos, aqueles que as ordens econômica e política, mundial e nacional, ameaçam em defesa de seus próprios interesses. 0 tempo da guerra e o tempo da paz pouco se diferenciam atualmente. Articulam-se de modo tão efetivo que não me parece possível discutir os horizontes da democracia sem discutir esse projeto que une guerra e religião entre nós ${ }^{36}$.

\section{Referências}

ALMEIDA, Ronaldo. A onda quebrada: evangélicos e conservadorismo. Cadernos PAGU, São Paulo, v. 50, p. 5-30, 2017. Disponível em: https://doi. org/10.1590/18094449201700500001. Acesso em: 6 ago. 2020.

36 Cf. COMAROFF, Jean; COMAROFF, John. Theory from the South: Or, How Euro-America is Evolving Toward Africa. Boulder: Paradigm Publishers, 2012.; GRAHAM, Stephen. Cidades sitiadas: o novo urbanismo militar. São Paulo: Boitempo, 2016.; MBEMBE, Achille. Necropolítica. Artes e Ensaios. Rio de Janeiro, v. 2, n. 32, p. 122-151, 2017. Disponível em: https://revistas.ufrj.br/index.php/ae/article/view/8993/7169. Acesso em: 6 ago. 2020. 
ASAD, Talal. Genealogies of Religion: Discipline and Power on Christianity and Islam. Baltimore: The Johns Hopkins University Press, 1993.

ASAD, Talal. Formations of the Secular: Christianity, Islam, Modernity. Stanford: Stanford University Press, 2003.

ASAD, Talal. Responses. In: SCOTT, David; HIRSCHKIND, Charles (orgs.). Powers of the Secular Modern: Talal Asad and His Interlocutors. Stanford: Stanford University Press, 2006.

ASAD, Talal. Secular Translations: Nation-State, Modern Self and Calculative Reason. New York: Columbia University Press, 2018.

ASAD, Talal; BROWN, Wendy; BUTLER, Judith; MAHAMOOD, Saba. Is Critique Secular? Blasphemy, Injury and Free Speech. California: University of California Press, 2009.

BIRMAN, Patrícia. Narrativas seculares e religiosas sobre a violência: as fronteiras do humano no governo dos pobres. Sociologia \& Antropologia, v. 9, n. 1, p. 111-134, 2019. Disponível em: https://doi.org/10.1590/223838752019v915. Acesso em: 6 ago. 2020.

BIRMAN, Patrícia; LEITE, Márcia Pereira. Rio e São Paulo: categorias emaranhadas e relativização dos seus sentidos nos estudos sobre (as chamadas) periferias. In: BARROS, Joana; COSTA, André Dal Boda da; RIZEK, Cibele (orgs.). Os limites da acumulação: movimentos e resistências nos territórios. São Carlos: IAU/USP, 2018.

BIRMAN, Patrícia; MACHADO, Carly. A violência dos justos: evangélicos, mídia e periferias da metrópole. Revista Brasileira de Ciências Sociais, v. 27, n. 80, p. 55-69, 2012. Disponível em: https://doi.org/10.1590/S010269092012000300004. Acesso em: 6 ago. 2020.

BURITY, Joanildo. A onda conservadora na política brasileira traz o fundamentalismo ao poder? In: ALMEIDA, Ronaldo; TONIOL, Rodrigo (org.). Conservadorismos, fascismos e fundamentalismos: análises conjunturais. Campinas: Ed. da Unicamp, 2018.

BURITY, Joanildo; CAMPOS, Maria das Dores Machado (orgs.). Os votos de Deus: Evangélicos, política e eleições no Brasil. Recife: Massangana, 2006. 
CAMURÇA, Marcelo. Religião, política e espaço público no Brasil: perspectiva histórico/sociológica e a conjuntura das eleições presidenciais de 2018. Estudos de Sociologia, Recife, v. 2, n. 25, 2019. Disponível em: https://periodicos.ufpe.br/revistas/revsocio/article/view/243765/34005. Acesso em: 6 ago. 2020.

CASANOVA, José. Secularism Revisite: A Reply to Talal Asad. In: Scott, David; HIRSCHKIND, Charles. Powers of the Secular Modern: Talal Asad and His Interlocutors. Stanford: Stanford University Press, 2006.

COMAROFF, Jean; COMAROFF, John. Theory from the South: Or, How EuroAmerica is Evolving Toward Africa. Boulder: Paradigm Publishers, 2012.

CONNOLY, William. Europe, a Minor Tradition. In: SCOTT, David; HIRSCHKIND, Charles (orgs.). Powers of Secular Modern: Talal Asad and His Interlocutors. Stanford: Stanford University Press, 2006.

DAS, Veena. Fronteiras, violência e o trabalho do tempo: alguns temas wittgensteinianos. Revista Brasileira de Ciências Sociais, Rio de Janeiro: Nova Fronteira/Faperj, v. 14, n. 40, p. 31-42, 1999. Disponível em: https://doi. org/10.1590/S0102-69091999000200003. Acesso em: 6 ago. 2020.

DAS, Veena. Secularism and the Argument from Nature. In: SCOTT, David; HIRSCHKIND, Charles (orgs.). Powers of the Secular Modern: Talal Asad and His Interlocutors. Stanford: Stanford University Press, 2006.

DAS, Veena. Violence, Gender, and Subjectivity. Annual Review of Anthropology, v. 37, p. 283-299, 2008.

FONSECA, Alexandre Brasil. Discursos evangélicos de uma Nova Direita à brasileira. In: SOLANO, Ester (org.). Brasil em colapso. São Paulo: Ed. da Unifesp, 2019.

GEERTZ, Clifford. A interpretação das culturas. Rio de Janeiro: LTC, 1989.

GIUMBELLI, Emerson. Símbolos religiosos em controvérsias. São Paulo: Terceiro Nome, 2014.

GRAHAM, Stephen. Cidades sitiadas: o novo urbanismo militar. São Paulo: Boitempo, 2016. 
HIRSCHKIND, Charles. Existe um corpo secular? Religião e Sociedade, v. 37, n. 1, p. 175-189, 2017. Disponível em: https://doi.org/10.1590/010085872017v37n1cap10. Acesso em: 6 ago. 2020.

LAMBECK, Michel; DAS, Veena; FASSIN, Didier; KEANE, Webb. Four Lectures on Ethics: Anthropological Perspectives. Chicago: HAU Books, 2015.

LEITE, Márcia Pereira. Entre o individualismo e a solidariedade: dilemas da cidadania e da política no Brasil. Revista Brasileira de Ciências Sociais, v. 15, n. 44, p. 73-90, 2000. Disponível em: https://doi.org/10.1590/S010269092000000300004. Acesso em: 6 ago. 2020.

LEITE, Márcia Pereira. La favela et la ville: de la production des "marges" à Rio de Janeiro. Brésil: Sciences humaines et sociales, n. 3, p. 109-128, 2013. Disponível em: https://journals.openedition.org/bresils/472. Acesso em: 6 ago. 2020.

MACHADO, Carly. Pentecostalismo e o sofrimento do (ex-)bandido: testemunhos, mediações, modos de subjetivação e projetos de cidadania nas periferias. Horizontes antropológicos, Porto Alegre, v. 20, n. 42, p. 153180, 2014.

MACHADO, Carly. The Church Helps the UPP, the UPP Helps the Church: Pacification Apparatus, Religion and Boundary Formation in Rio de Janeiro's Urban Peripheries. Vibrant: Virtual Brazilian Anthropology, v. 14, n. 3, 2017.

MAHMOOD, Saba. Politics of Piety: The Islamic Revival and the Feminist Subject. Princeton: Princeton University Press, 2012.

MARIANO, Ricardo. Neopentecostais: sociologia do novo pentecostalismo no Brasil. São Paulo: Loyola, 1999.

MARIANO, Ricardo. Laicidade à brasileira: católicos, pentecostais e laicos em disputa na esfera pública. Civitas, Porto Alegre, v. 11, n. 2, p. 238-258, 2011. Disponível em: https://doi.org/10.15448/1984-7289.2011.2.9647. Acesso em: 6 ago. 2020.

MARIZ, Cecília. A teologia da b espiritual: uma revisão da literatura socioantropológica. Revista brasileira de informação bibliográfica em Ciências Sociais, n. 47, p. 33-48, 1999. 
MARIZ, Cecília. Rainha dos anjos: a aparição de Nossa Senhora em Itaipu, Niterói. In: STEIL, Carlos Alberto; MARIZ, Cecília; REESINK, Misia (orgs.). Maria entre os vivos: reflexões teóricas e etnografias sobre aparições marianas no Brasil. Porto Alegre: Ed. da UFRGS, 2003.

MBEMBE, Achille. Necropolítica. Artes e Ensaios. Rio de Janeiro, v. 2, n. 32, p. 122-151, 2017. Disponível em: https://revistas.ufrj.br/index.php/ae/article/ view/8993/7169. Acesso em: 6 ago. 2020.

MIRANDA, Júlia. Estado laico no Brasil: entre sofismas e ambiguidades. Cultura y Religión, Santiago de Chile, v. 7, n. 2, p. 69-85, 2013.

MONTERO, Paula. Religião cívica, religião civil, religião pública: continuidades e descontinuidades. Debates do NER, Porto Alegre, v. 1, n. 33, p. 15-39, 2018. Disponível em: https://doi.org/10.22456/1982-8136.88037. Acesso em: 6 ago. 2020.

NOGUEIRA, Kiko. "Ministra brasileira conta fábulas sexuais sobre a Holanda": maiores jornais holandeses denunciam fake news de Damares. DCM, 24 jan. 2019. Disponível em: https://www.diariodocentrodomundo.com.br/ministrabrasileira-conta-fabulas-sexuais-sobre-a-holanda-maiores-jornaisholandeses-denunciam-fake-news-de-damares/. Acesso em: 6 ago. 2020.

OOSTERBAAN, Martijn; MACHADO, Carly. Postsecular Pacification: Pentecostalism and Military Urbanism in Rio de Janeiro. Cultures, Citizenship, and Human Rights. London: Routledge, 2019. No prelo.

ORO, Ari Pedro. A laicidade no Brasil e no Ocidente. Algumas considerações. Civitas, Porto Alegre, v. 11, n. 2, p. 221-237, 2011. Disponível em: https://doi. org/10.15448/1984-7289.2011.2.9646. Acesso em: 6 ago. 2020.

QUADROS, Marcos Paulo Reis; MADEIRA, Rafael Machado. Fim da direita envergonhada? Atuação da bancada evangélica e da bancada da bala e os caminhos da representação do conservadorismo no Brasil. Opinião Pública, Campinas, v. 24, p. 486-522, 2018. Disponível em: https://doi. org/10.1590/1807-01912018243486. Acesso em: 6 ago. 2020.

RABELO, Thiago Pereira. "Um seguro para a paz": ensaio sobre políticas de combate ao terrorismo, do PATRIOT Act norte-americano (2001) à Lei Antiterrorismo brasileira ( $\left.n^{\circ} 13.260 / 2016\right), 2019$. Dissertação (Mestrado 
em Ciências Sociais) - Programa de Pós-graduação em Ciências Sociais, Universidade Estadual do Rio de Janeiro, Rio de Janeiro, 2019.

SAÏD, Edward W. Orientalismo: o Oriente como invenção do Ocidente. São Paulo: Companhia das Letras, 1978.

SALES, Lilian; MARIANO, Ricardo. Ativismo político de grupos religiosos e luta por direitos. Religião e Sociedade, Rio de Janeiro, v. 39, n. 2, 2019. Disponível em: http://dx.doi.org/10.1590/0100-85872019v39n2editorial. Acesso em: 6 ago. 2020.

SCOTT, David; HIRSHKIND, Charles. Introduction: The Anthropological Skepticism of Talal Asad. In: SCOTT, David; HIRSHKIND, Charles (orgs.). Powers of the Secular Modern: Talal Asad and His Interlocutors. Stanford: Stanford University Press, 2006.

SCOTT, Joan Wallach. Sex and Secularism. Princeton: Princeton University Press, 2018.

THEIJE, Marjo; JACOBS, Els. Gênero e aparições marianas no Brasil contemporâneo. In: STEIL, Carlos Alberto; MARIZ, Cecília; REESINK, Misia (orgs.). Maria entre os vivos: reflexões teóricas e etnografias sobre aparições marianas no Brasil. Porto Alegre: Ed. da UFRGS, 2003.

SILVA, Luiz Antonio Machado da. O controle do crime violento no Rio de Janeiro. Le Monde Diplomatique, 1 fev. 2013. Disponível em: https://diplomatique.org. br/o-controle-do-crime-violento-no-rio-de-janeiro/. Acesso em: 6 ago. 2020. 